
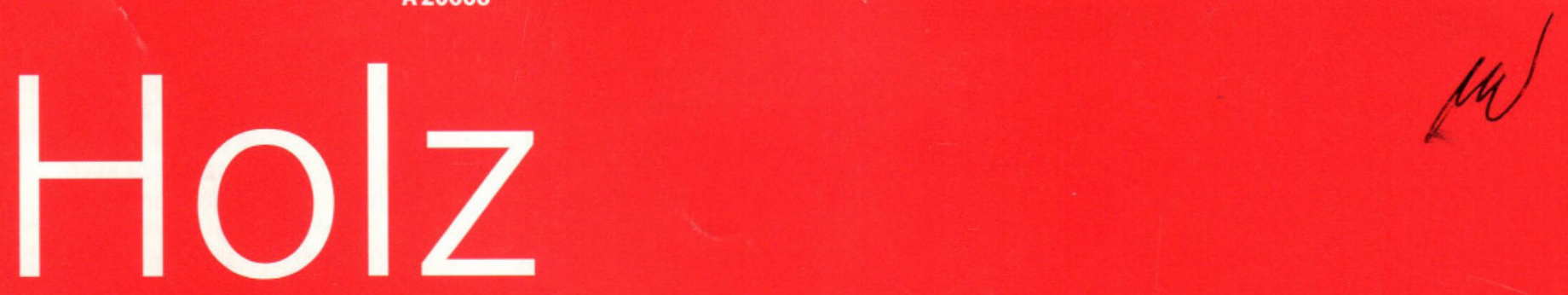

als Roh- und Werkstoff

European Journal of Wood and Wood Products

\title{
Volume 55
}

- Number 5

September 1997

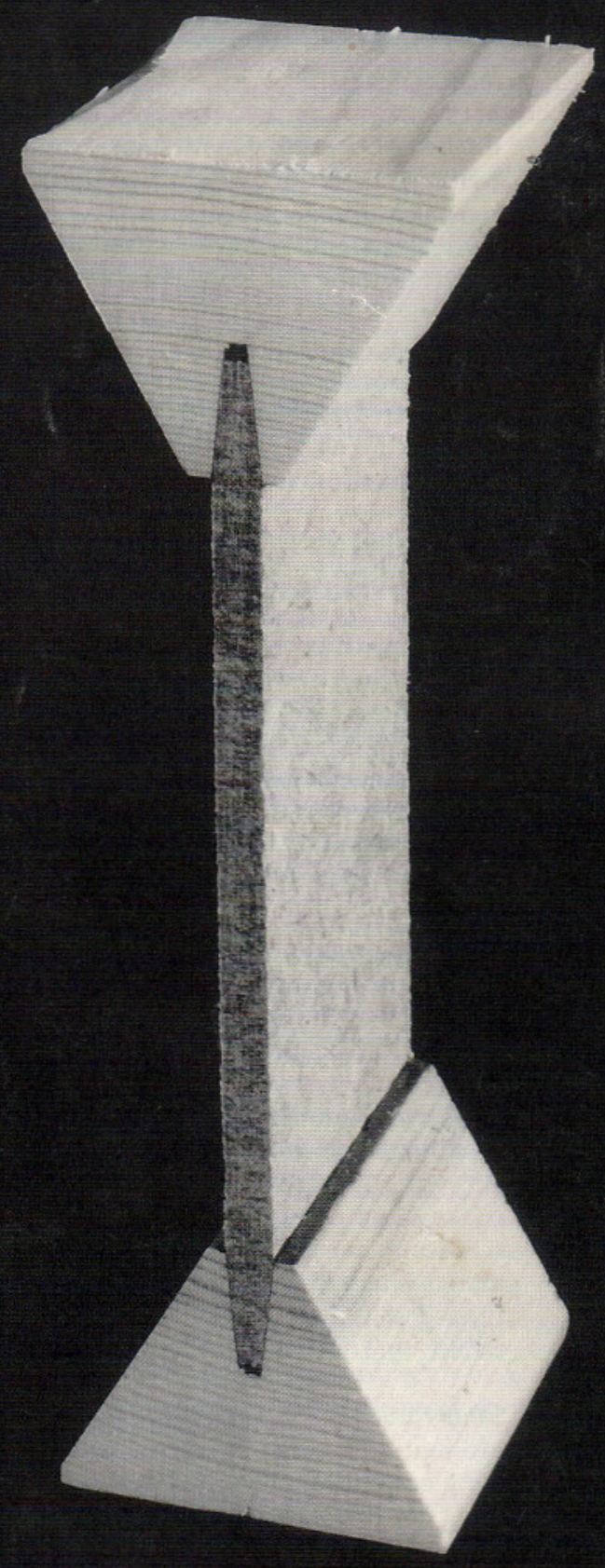


Bending strength of I-beams with webs of wood-fibre board and flanges of star-sawn triangular profiles.

D. Sandberg

M. Stehr

Royal Institute of Technology, Dept. of Manufacturing Systems, Division of Wood Technology and Processing, S-100 44 Stockholm, Sweden

\section{Subject}

To determine some bending strength parameters of I-beams with triangular flanges and wood-fiber board webs.

\section{Material and methods}

Twenty three beams with wood-fiber board webs K-board K40 (BFS 1993) and triangular flanges of pine (Pinus silvestris $L$ ) prepared by star-sawing (Sandberg 1996) were prepared and loaded in bending to failure (Fig 1). The flanges were considered to be a structural lumber K24 or lower (BFS 1993). The cross-sectional dimensions of the beams are given in Fig 2. The flanges and webs were glued using a resorcinol-formaldehyde adhesive (Cascosinol 1711, hardener 2520). The beams were loaded to failure using a four-point loading technique (Nordtest-standard 1987), and the failure load, modulus of elasticity and ultimate moment to failure were determined. During the experiment, the mean moisture content and the density of the flanges were $10.3 \%$ and $417 \mathrm{Kg} / \mathrm{m}^{3}$ respectively.

\section{Results}

Table 1 shows the mean values for 23 beams loaded in bending to failure. The results obtained are equivalent to an I-beam with a rectangular cross section flange having the same section modulus as the triangular flange.

Compared to solid cross-section beams, an I-beam has the advantage of providing the greatest moment of inertia for the amount of material employed. Using an I-beam with a triangular flange rather than a rectangular flange, it is possible to achieve additional advantages such as:

- A better material utilization, where a 7\% small volume of wood is needed in a triangular flange to give the same section modulus as a rectangular flange.

- Since it is free from the undesirable juvenile wood, a beam with a triangular flange can offer a high density structure with a better shape and dimensional stability

- The beam can offer a better shape stability if the triangular flange is glued to the web, since the position of the annual ring orientation is maintained as shown in Fig 2. 


\section{References}

BFS 1993: Boverkets konstruktionsregler 94, Boverket 1993:58, ISSN

1100-0856 (in Swedish)

Nordtest method 1987: Light-weight beams of wood, NT Build 327

Sandberg, D. 1996: Radially sawn timber. Star-sawing - a new

method for producing timber with vertical annual rings. Holz als

Roh- und Werkstoff 54(1996) 145-151

Table 1. Strength values in bending for the beams in the test (mean values of 23 beams at $10.3 \%$ moisture content)

\begin{tabular}{llll}
\hline Property & Mean value & & Standard deviation \\
\cline { 1 - 1 } Momentkapacitet $(\mathrm{kNm})$ & 11,2 & & 3,3 \\
Bending resistance $\left(\mathrm{kNm}^{2}\right)$ & 392 & 66,9 \\
Kantböjhållfasthet $(\mathrm{MPa})$ & 35,7 & 10,5 \\
Modulus of elasticity $(\mathrm{GPa})$ & 10,9 & 1,7 \\
Failure load $(\mathrm{kN})$ & 16,9 & 5,0 \\
\hline
\end{tabular}

Fig. 1. Cross-section of a conventional light-weight beam (left) and a light-weight beam with triangular flanges (right)

Fig. 2. Cross-section dimension for the beam in the investigation. The length of the beams was $4.2 \mathrm{~m}$ 


$$
\text { II }
$$




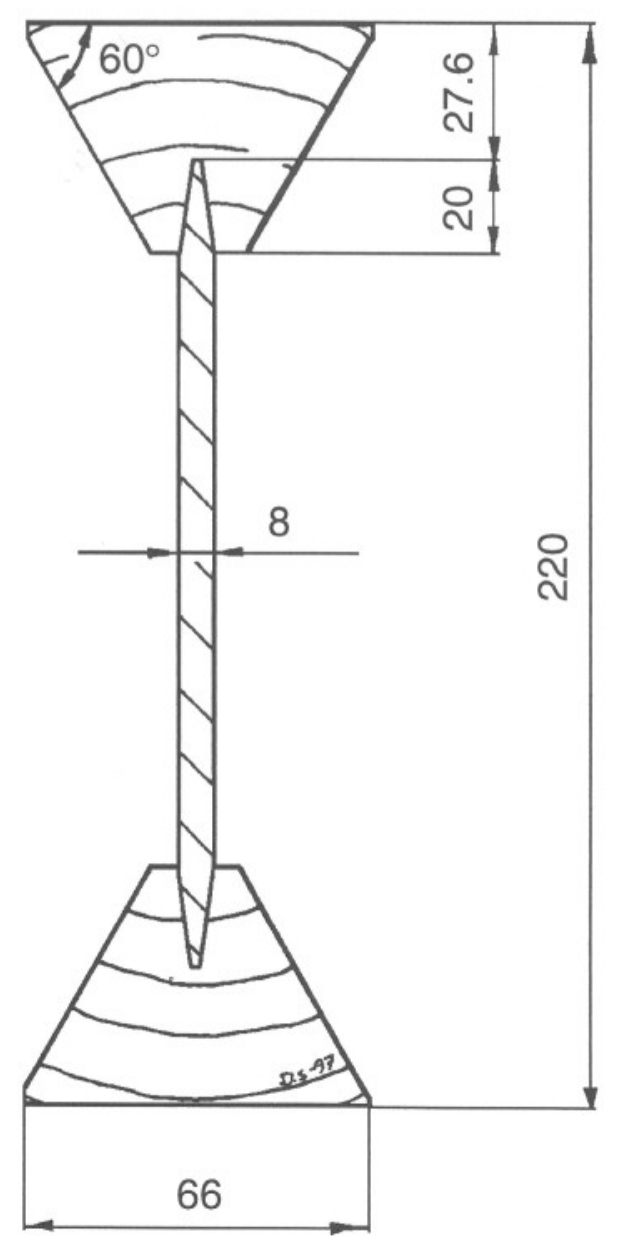

